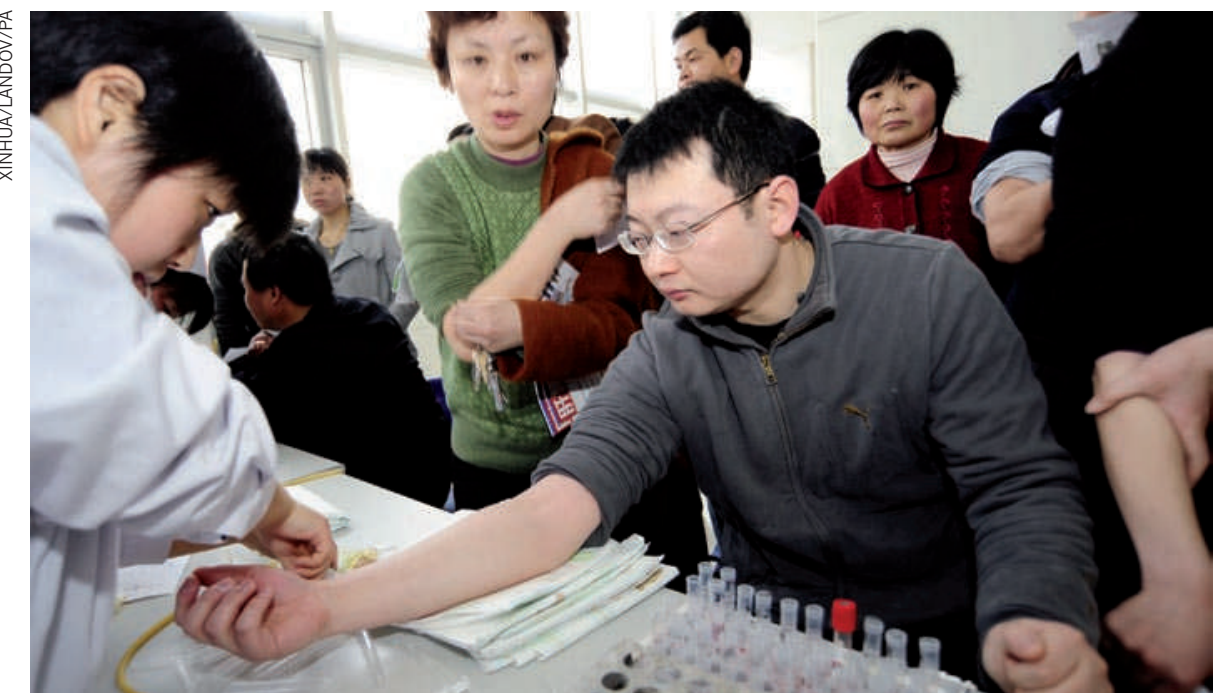

Proteomics could turn up biomarkers to help diagnose disease faster than current tests.

\title{
BIOTECHNOLOGY
}

\section{China pushes for the proteome}

\section{Strategy to build a complete catalogue of human proteins could put the country in a leading position.}

\section{BY DAVID CYRANOSKI}

$\mathrm{F}$ irst the genome; now the proteome. China has already established a leading position in DNA sequencing through the work of the BGI in Shenzhen (formerly the Beijing Genomics Institute), which has been generating eye-catching genomics discoveries for the past few years (see Nature 464, 22-24; 2010). This week, Chinese researchers are set to announce initiatives that could put them at the forefront of international efforts to catalogue and characterize all proteins in the human body.

Inspired by the Human Genome Project, protein researchers worldwide have been seeking funds to build a full catalogue of human proteins - a proteome - which, they say, will explain how the information encoded in our genomes can give rise to normal and diseased states.

This January, the Human Protein Organization (HUPO) in Montreal, Canada, took the first steps towards an international effort. It set up the Human Proteome Project (HPP) working group to coordinate researchers who are characterizing the products of the 21,000 or so protein-coding genes in the human genome (see Nature 452, 920-921; 2008). But funding agencies worldwide have yet to show full support for the scheme, which is likely to carry a multibillion-dollar price tag. There is also uncertainty over the scope of the project - each human protein can be modified in an as-yet-unspecified number of ways - and over how well data from different labs can be compared (A. W. Bell et al. Nature Methods 6, 423-430; 2009).

The lack of obvious medical applications has also deterred funders, says Tommy Nilsson, a proteomics specialist at McGill University in Montreal. "Hundreds of millions have gone into proteomics already, with very little to show for it," he says. Proteomic analyses of blood and plasma have turned up protein biomarkers for diseases that have not survived closer scrutiny, says Nilsson.

However, this week, Chinese researchers travelled to HUPO's annual congress in Sydney, Australia, to announce plans that defy such scepticism. The Beijing Proteome Research Center, directed by biochemist He Fuchu, has received average grants of roughly 200 million renminbi (US\$30 million) per year as one of several institutes involved in HUPO's Human Liver Proteome Project (see Nature 425, 441; 2003). That budget, He says, is soon set to double as the initiative - now renamed the Chinese Human Proteome Project - expands to cover proteins in the blood, brain, lungs, skin and other organs. The Chinese government also plans to invest 1.2 billion renminbi in a national laboratory called the Pilot Hub of Encyclopedical proteomIX (PHOENIX) which has been several years in the planning.

"The investment is impressive and unprecedented," says Ruedi Aebersold, a proteomics expert at the Swiss Federal Institute of Technology in Zurich and a member of the HPP working group. "The launch of a large project in China would give the whole HPP project a significant boost."

The PHOENIX project will include a doubling of facilities for nuclear magnetic resonance imaging at Peking University, already the largest facility for structure determination in China but heavily oversubscribed. Tsinghua University's electron microscope facility will be expanded, and there will be more capacity for proteinstructure studies at the Institute of Biophysics of the Chinese Academy of Sciences in Beijing.

\section{PROTEIN PIPELINE}

But the core of the project, and half the budget, will go to He's new mass spectroscopy centre, to be built near the Beijing Proteome Research Center. The cash will buy 20 new mass spectrometers, bringing the total number in the centre to 29 . They will be integrated with a robotic pipeline for high-throughput processing of proteins, including bioinformatic analysis. It will be the "first laboratory in the world to reach that level of integration", says He.

China's human proteome project will build on the success of He's liver project, which he says produced the largest human organ proteome to date, encompassing nearly 7,000 proteins (A. Sun et al. J. Proteome Res. 9, 50-58; 2010). At the Sydney meeting, He plans to discuss unpublished work that maps protein-protein interactions and their localization. "It's a real, comprehensive demonstration for other organs," he says.

He has already recruited Jun Qin of Baylor College of Medicine in Houston, Texas, as chief technical officer of the mass spectrometry centre. Qin says that some $30-50$ groups will be established to carry out projects "covering the majority of major organs" using the PHOENIX facilities. Human resources will be a problem, and he plans to visit the BGI to seek advice on how to establish a large-scale facility quickly. "PHOENIX is the ideal place. In the United States, they don't do things in such a centralized fashion," says Qin.

McGill University's John Bergeron, a member of HUPO's board of directors, agrees. "I was a bit dismayed when I visited the US National Institutes of Health to see no less than three different institutes doing liver proteomics with no communication among them."

But the value of the Chinese effort will depend on the quality of the data it produces. "Data analysis is the heart of proteomics. The Chinese data are undergoing rigorous analysis now and we should know their value shortly," says Bergeron. If the data are found to be up to scratch, "China could well take the lead" in pushing proteomics forward, he says. 